\title{
Analysis of Patients with 1988 FIGO Stage-II Endometrial Cancer
}

\author{
Isin UREYEN ${ }^{1}$, Taner TURAN ${ }^{1}$, Gunsu KIMYON ${ }^{1}$, Alper KARALOK ${ }^{1}$, Tolga TASCI ${ }^{1}$, \\ Nurettin BORAN ${ }^{1}$, Gokhan TULUNAY ${ }^{1}$, M. Faruk KOSE ${ }^{2}$
}

${ }^{1}$ Etlik Zubeyde Hanim Women's Health Training and Research Hospital, Depertment of Gynecologic Oncology, Ankara

${ }^{2}$ Bahcesehir University School of Medicine, Department of Obstetrics and Gynecology, Istanbul, TURKEY

\begin{abstract}
Management of stage II endometrial cancer still has many controversies. We evaluated patients with stage II (FIGO 1988) endometrial cancer operated in our clinic in terms of treatment modalities, surgico-pathological factors, recurrence rates and patterns. Fifty-three patients with 1988 FIGO stage II endometrial cancer who underwent staging surgery between January 1993 and December 2012 were included in this study. The mean age of the patients was 57 years. Cervical invasion couldn't be detected in the preoperative pelvic examination in 47 patients (88.7\%). Thirty-eight patients received simple hysterectomy $(\mathrm{SH})$ and 15 patients had radical hysterectomy $(\mathrm{RH})$. All patients received pelvic and paraaortic lymphadenectomy. Forty-two patients took adjuvant radiotherapy. The median follow-up time of the patient population was 39 months (range 1-139 months). Recurrence was observed in four patients. There was no statistically significant difference between the $\mathrm{RH}$ and $\mathrm{SH}$ groups in terms of recurrence $(\mathrm{p}=0.53)$. Advanced age, deep myometrial invasion and the lower number of harvested lymph nodes were associated with recurrence. Systemic adjuvant therapy may be involved in the first-line treatment plan in order to prevent distant failures, since they continue to be responsible for the most of the recurrences and mortality despite radical surgeries and different protocols of adjuvant radiotherapy.
\end{abstract}

Keywords: Endometrial cancer, Cervical invasion, Survival, Lymphadenectomy

\section{ÖZET}

\section{FIGO Evrelemeseni Göre Evre II Endometrium Kanseri Olan Hastaların Analizi}

Evre II endometriyum kanserinin yönetimi hala tartışmalıdır. Kliniğimizde opere olan evre II endometriyum kanseri olan hastaları tedavi çeşitleri, cerrahi-patolojik faktörler, rekürrens şekli ve sıklığı açısından değerlendirdik. Çalışmaya Ocak 1993 ve Ekim 2012 tarihleri arasında evreleme cerrahisi geçiren evre II endometriyum kanseri olan 53 hasta dahil edildi. Hastaların ortalama yaşı 57 idi. Servikal invazyon 47 hastanın (\%88.7) preoperatif incelemesinde saptanamadı. Otuz-sekiz hastaya basit histerektomi $(\mathrm{BH})$ ve 15 hastaya radikal histerektomi $(\mathrm{RH})$ yapıldı. Tüm hastalara pelvik ve paraaortik lenfadenektomi yapıldı. Kırk-iki hasta adjuvan radyoterapi aldı. Hastaların ortalama takip süresi 39 aydı (aralık, 1-139). Rekürrens 4 hastada gelişti. RH ve BH grupları arasında rekürrens açısından farklılık yoktu ( $p=0.53)$. Illeri yaş, derin myometrial invazyon ve az sayıda lenf nodu çıkartılması rekürrens ile ilişkiliydi. Evre II endometriyum kanserinde radikal cerrahilere ve farklı adjuvan radyoterapi protokollerine rağmen rekürrenslerin ve mortalitenin esas sorumlusu uzak metastazlardır. Bundan dolayı, uzak metastazları engelleyebilmek için sistemik adjuvan tedavi bu hastalığın birinci basamak tedavisinde düşünülebilir.

Anahtar Kelimeler: Endometriyum kanseri, Servikal invazyon, Sağkalım, Lenfadenektomi 


\section{INTRODUCTION}

Endometrial cancer is the second most frequent genital cancer following ovarian cancer and it is the seventh most frequent cancer in women in Turkey according to the 2010 Ministry of Health data. In 2010, 1364 new cases of endometrial cancer were defined and 726 patients died of endometrial cancer. ${ }^{1}$ Most of the patients with endometrial cancer are detected in stage I having a survival rate of almost $90 \%$. However, this figure falls to $70 \%$ for patients with stage II disease that constitutes approximately $12 \%$ of endometrial cancer cases. ${ }^{2}$

Modifications have been made in the staging system of endometrial cancer. When surgical staging instead of clinical staging was introduced by FIGO (International Federation of Gynecology and Obstetrics) in 1988, stage II disease was defined pathologically and divided into two substages as stage IIa with endocervical glandular involvement only and as stage IIb with tumor extending to the cervical stroma without extrauterine involvement. ${ }^{3}$ In 2009 , FIGO redefined stage II disease only as the stromal involvement of cervix. ${ }^{4}$

Despite these changes in the staging system of endometrial cancer, management of stage II disease still has many controversies regarding the type of the hysterectomy; simple extrafascial vs. radical, the necessity and extent of lymphadenectomy and the role, type and timing of radiotherapy. Low incidence of the disease, difficulties in preoperative diagnosis of cervical involvement and the limited number of studies including fully staged patients are considered to be the reasons.

In the present study, patients with stage II (FIGO 1988) endometrial cancer operated in our clinic were evaluated in terms of treatment modalities, surgico-pathological factors, recurrence rates and patterns.

\section{PATIENTS AND METHODS}

Fifty-three patients with 1988 FIGO stage II endometrial cancer who underwent staging surgery between January 1993 and December 2012 were included in this study. Although FIGO altered the staging system in 2009 and doesn't use substages of stage II disease today, we evaluated the patients according to FIGO 1988 staging system in order to be able to interpret and compare our data with the former studies in the literature. Patients without systematic pelvic and paraaortic lymphadenectomy, patients with uterine sarcoma or sarcomatous component and patients whose final pathology and medical reports couldn't be obtained were excluded. While the surgico-pathological data was obtained from final pathology reports, the demographic data was taken from the electronic database. The data collected and evaluated in detail were age at diagnosis, histology, grade, depth of myometrial invasion, lymphovascular space invasion (LVSI), number and status of lymph nodes harvested, type of surgery, type of adjuvant therapy, occurrence and management of recurrence and last follow-up. The time from the surgery to the last visit was defined as follow-up time.

In our clinic, cervical biopsy isn't used routinely in patients with endometrial cancer. Nevertheless, patients are evaluated for the existence of cervical involvement when there is doubt. Cervical biopsy and/or endocervical curettage are performed with this purpose. Type II or type III radical hysterectomy (RH) and pelvic and paraaortic lymphadenectomy are considered for patients with a preoperative diagnosis of cervical involvement. Frozen/section (FS) is utilized intraoperatively in our clinic and staging surgery is performed for the patients whose FS revealed non-endometrioid adenocancer, grade 2 or 3 disease, the depth of myometrial invasion being $1 / 2$ or greater, cervical involvement and a tumor size $>2 \mathrm{~cm}$. When cervical involvement is detected intraoperatively, parametrectomy and systematic pelvic and paraaortic lymphadenectomy are performed. When cervical involvement is defined preoperatively or intraoperatively and then extrauterine spread (lymph node or omental metastasis) is recognized intraoperatively, simple hysterectomy ( $\mathrm{SH})$ is performed instead of RH. Following treatment options are offered for the patients who had SH and bilateral salphingo-oophorectomy and had a diagnosis of cervical involvement in the paraffin block; 1) Radical parametrectomy and systematic pelvic and paraaortic lymphadenectomy, 2) Systematic pelvic and paraaortic lymphadenectomy, 3) Adjuvant treatment (radiotherapy and/or chemotherapy).

Descriptive statistics were calculated using the SPSS (Statistical Package for Social Sciences) 17.0 package program (SPSS Inc, Chicago IL, USA). The nominal values and the differences between the 


\begin{tabular}{|c|c|c|}
\hline Parameter & n / Mean & $\begin{array}{l}\text { \%/Median } \\
\text { (Range) }\end{array}$ \\
\hline Age & 57 & $57(35-92)$ \\
\hline Tumor size (mm) & 52 & $51(10-110)$ \\
\hline \multicolumn{3}{|l|}{ Tumor type } \\
\hline Endometrioid & 43 & 81.1 \\
\hline Clear cell & 2 & 3.8 \\
\hline Serous & 2 & 3.8 \\
\hline Mix & 6 & 11.3 \\
\hline \multicolumn{3}{|l|}{ Grade } \\
\hline 1 & 19 & 35.8 \\
\hline 2 & 16 & 30.2 \\
\hline 3 & 18 & 34 \\
\hline \multicolumn{3}{|c|}{ Depth of myometrial invasion } \\
\hline No invasion & 4 & 7.5 \\
\hline$<1 / 2$ & 25 & 47.2 \\
\hline$\geq 1 / 2$ & 24 & 45.3 \\
\hline \multicolumn{3}{|l|}{ Cervical invasion } \\
\hline Glandular spread & 9 & 17 \\
\hline Stromal invasion & 44 & 83 \\
\hline \multicolumn{3}{|c|}{ Lymphovascular space invasion } \\
\hline Negative & 30 & 56.6 \\
\hline Positive & 15 & 28.3 \\
\hline Not reported & 8 & 15.1 \\
\hline \multicolumn{3}{|c|}{ Number of harvested lymph nodes } \\
\hline Paraaortic & 19 & $18(3-46)$ \\
\hline Pelvic & 43 & 39 (16-82) \\
\hline
\end{tabular}

ratios were evaluated with Chi-Square. The cut-off for statistical significance was set at $\mathrm{p}<0.05$.

\section{RESULTS}

\section{Surgico-pathological Analysis}

Fifty-three (10\%) among 525 patients who were surgically staged in our clinic for endometrial cancer between January 1993 and December 2012 had cervical involvement without extrauterine disease.

The median age of the patients was 57 years and ranged between 35 and 92 years. The stage was IIa in nine patients and IIb in 44 patients according to
FIGO 1988. Among the nine patients with stage IIa disease, five patients had stage Ia and four patients had stage Ib disease according to the 2009 FIGO criteria. Three patients had synchronous ovarian tumors. Forty-three patients had endometrioid type tumor and 19,16 and 18 patients had grade 1,2 and 3 disease, respectively. Myometrial invasion wasn't observed in four patients and 24 patients had myometrial invasion being $1 / 2$ or greater. While LVSI was detected in 15 patients, it wasn't reported in paraffin blocks in eight patients. Cytology wasn't taken in three patients and omental sampling wasn't performed in three patients. Surgico-pathological characteristics were shown in detail in Table 1.

Cervical invasion couldn't be detected in the preoperative pelvic examination in 47 patients $(88.7 \%)$. In one of these patients, endocervical curettage was performed with suspicion, but this procedure couldn't reveal cervical invasion. On the other hand, cervical involvement was diagnosed in six patients $(11.3 \%)$ preoperatively. Of these six patients, diagnosis was made with endocervical curettage in two patients and with cervical biopsy in four. Intraoperatively diagnosed cervical involvement was detected with FS in five patients and with intraoperative examination in two patients. Totally seven patients (13.2\%) were detected intraoperatively.

Of the 53 patients, 40 patients had SH and 13 had $\mathrm{RH}$ in the first operation. Two patients in the SH group had parametrectomy following the first operation in order to convert $\mathrm{SH}$ to $\mathrm{RH}$. In conclusion, 38 patients received simple hysterectomy (SH) and 15 patients had RH. In four patients in the $\mathrm{SH}$ group, lymphadenectomy was performed as a second operation following the first operation due to the discordance between frozen/section and paraffin block results. Two patients in the RH group had type III hysterectomy and remaining 13 patients had type II hysterectomy. All patients received pelvic and paraaortic lymphadenectomy. The mean number of removed lymph nodes was 62 (range: 28-108). This figure was 43 (range: 16-82) and 19 (range: 3-46) for the pelvic and paraaortic regions, respectively.

Forty-two patients took adjuvant radiotherapy. Among the 38 patients having simple hysterectomy, three patients didn't have adjuvant treatment, since they had only endocervical glandular involvement. Twenty-nine of 35 patients had only radiotherapy, three patients had only platinum based chemother- 


\begin{tabular}{|c|c|c|c|c|}
\hline \multirow[t]{2}{*}{ Parameter } & \multicolumn{3}{|c|}{ Patient no } & \multirow[b]{2}{*}{4} \\
\hline & 1 & 2 & 3 & \\
\hline Age & 58 & 58 & 75 & 81 \\
\hline FIGO 1988 Stage & $\| B$ & $\| \mathrm{B}$ & IIB & $\| \mathrm{B}$ \\
\hline Tumor size (mm) & 15 & 50 & 30 & 55 \\
\hline Tumor type & Endometrioid & Endometrioid & Endometrioid & Mix \\
\hline $\begin{array}{l}\text { Depth of myometrial } \\
\text { invasion }\end{array}$ & $\geq 1 / 2$ & $\geq 1 / 2$ & $\geq 1 / 2$ & $\geq 1 / 2$ \\
\hline Grade & 2 & 2 & 1 & 1 \\
\hline $\begin{array}{l}\text { Lymphovascular } \\
\text { space invasion }\end{array}$ & Yes & No & No & Yes \\
\hline First operation & $\begin{array}{l}\text { Type I Hysterectomy } \\
\text { + Lymphadenectomy }\end{array}$ & $\begin{array}{l}\text { Type II Hysterectomy + } \\
\text { Lymphadenectomy }\end{array}$ & $\begin{array}{l}\text { Type III Hysterectomy + } \\
\text { Lymphadenectomy }\end{array}$ & $\begin{array}{l}\text { Type I Hysterectomy + } \\
\text { Lymphadenectomy }\end{array}$ \\
\hline Second operation & Not done & - & - & Not done \\
\hline Adjuvant therapy & Yes & No & No & Yes \\
\hline Type of adjuvant therapy & Radiotherapy & - & - & Radiotherapy \\
\hline Disease-free survival (month) & 17 & 13 & 33 & 22 \\
\hline Recurrence site & Pulmonary & Pelvic & Pelvic & Pelvic + Pulmonary \\
\hline Recurrence Treatment & $\begin{array}{l}\text { Pulmonary resection + } \\
\text { Mediastinal lymph node } \\
\text { dissection + Platinum } \\
\text { based-CT }\end{array}$ & $\begin{array}{l}\text { Debulking + Platinum } \\
\text { based-CT + RT } \\
\text { (treatment continues) }\end{array}$ & $\begin{array}{l}\text { Debulking + Platinum } \\
\text { based-CT (only } 1 \text { cycle } \\
\text { because of toxicity) }\end{array}$ & Platinum based-CT \\
\hline Last status & Alive without disease & Alive with disease & Alive without disease & Died of Disease \\
\hline Overall survival & & & & 38 \\
\hline Follow-up time & 72 & 18 & 57 & 38 \\
\hline
\end{tabular}

apy and the last three patients had a combination of radiotherapy and platinum based chemotherapy. Among the 15 patients having radical hysterectomy, eight patients didn't have adjuvant treatment, five patients took radiotherapy, one patient took platinum based chemotherapy and one patient took a combination of radiotherapy and platinum based chemotherapy.

Four patients who took only chemotherapy had been decided to be given a combination of radiotherapy and platinum based chemotherapy. Two had synchronous ovarian tumors and two had clear cell tumors. However, two of them couldn't take RT because of the bone morrow toxicity of chemotherapy. The other patients were lost to follow up during chemotherapy
Since the patients were referred to other clinics for radiotherapy, details of radiotherapy including protocols and toxicity couldn't be obtained.

\section{Recurrence}

Eleven patients who were lost to follow-up after surgery weren't included in the recurrence analysis. The median follow-up time of the patient population was 39 months (range 1-139 months). Recurrence was observed in four patients $(9.5 \%)$ among the 42 patients who were included. The mean time from surgery to recurrence was 21.3 months $(13,17$, 22,33 months). Two of these four patients had had $\mathrm{RH}$ and other two patients had had SH and adjuvant radiotherapy for their initial management. The detailed data of the four patients having recurrence 
International Journal of Hematology and Oncology

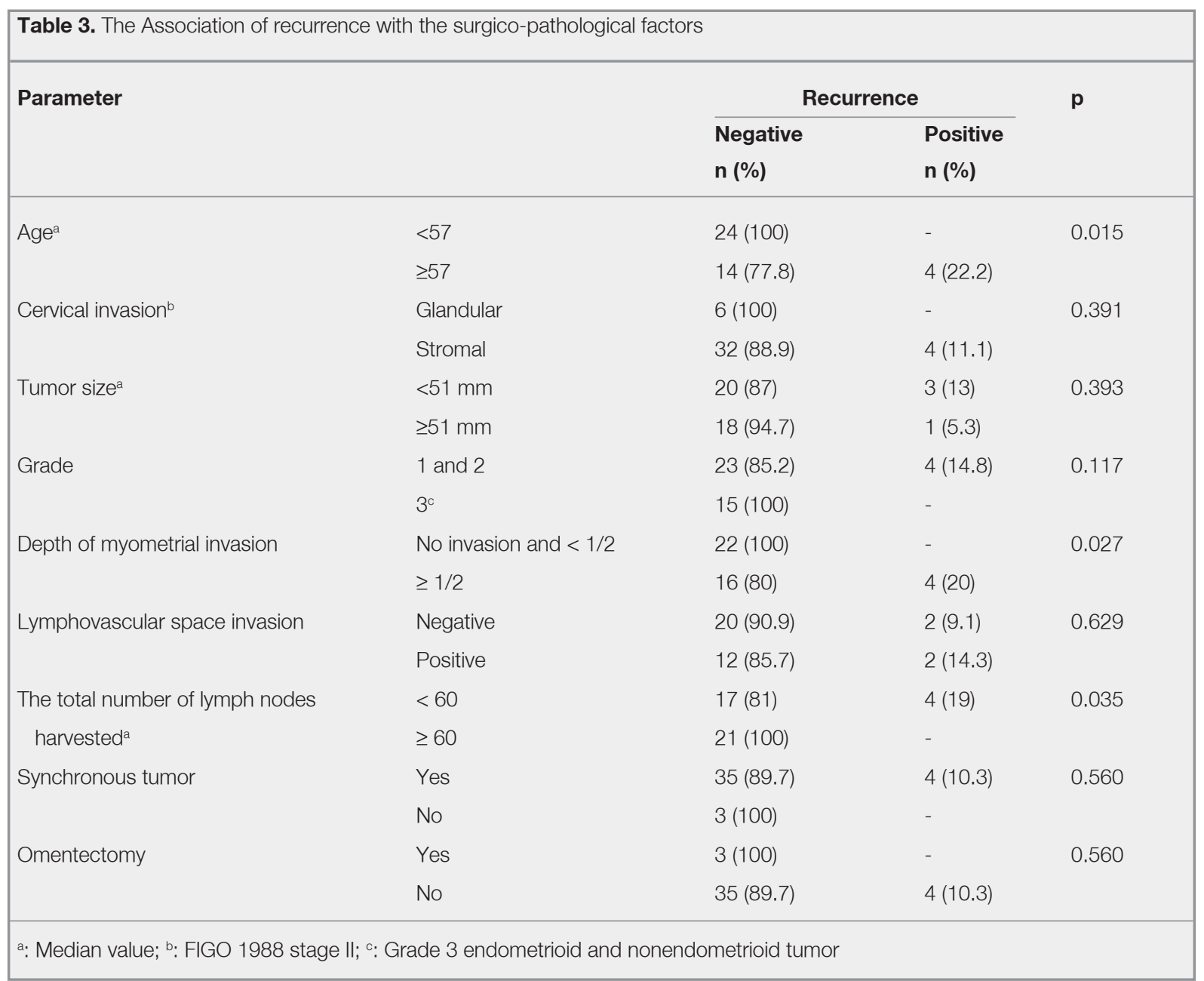

were shown in Table 2. All these four patients had cervical stromal invasion and myometrial invasion being $1 / 2$ or greater. Recurrence developed in lung in two patients having $\mathrm{SH}$ and adjuvant radiotherapy as the initial treatment (patients 1,4), one of which had also tumor in the pelvis (patient 4). Recurrence was only in the pelvis in two patients having $\mathrm{RH}$ without adjuvant radiotherapy (patients 2,3). There was no statistically significant difference between the $\mathrm{RH}$ and $\mathrm{SH}$ groups in terms of recurrence $(\mathrm{p}=$ $0.53)$.

In the follow-up period, only one patient $(2.4 \%)$ died of disease (patients 4) (Table 2). SH and systematic bilateral pelvic and paraaortic lymphadenectomy were performed for this patient in the initial operation. The patient had adjuvant radiotherapy and recurrence was detected in the pelvis and lung 22 months following surgery. She was given platinum based chemotherapy and died of disease after 16 months.

In the patient population, advanced age, deep myometrial invasion and the lower number of harvested lymph nodes were associated with recurrence (Table 3). Recurrence wasn't observed in 11 patients who didn't have any of these risk factors, while three of eight patients having all these three risk factors had recurrence $(p=0.010)$. Nevertheless, there was no relationship between recurrence and the type of cervical involvement (glandular or stromal), grade, LVSI and associated synchronous tumor. 


\section{DISCUSSION}

Involvement of the cervix in endometrial cancer is a poor prognostic factor. ${ }^{5}$ Although the importance of cervical involvement was first defined by Heyman et al. in $1941^{6}$ and it was included in the staging system in $1963^{7}$, the management of stage II endometrial cancer is still controversial.

Surgery seems to be the cornerstone of the treatment beyond dispute. However, debates regarding type of surgery, necessity and extent of lymphadenectomy and the management of patients diagnosed postoperatively continue. In 1998, the analysis of SEER data showed that among the patients with stage II endometrial cancer, 5-year survival rate was 93\% with radical hysterectomy and $84 \%$ with simple hysterectomy $(\mathrm{p}<0.05) .{ }^{8}$ Mariani et al. observed no recurrence in patients with surgical stage II endometrial cancer who had RH regardless of the use of adjuvant radiotherapy. ${ }^{9}$ In the studies by Eltabbakh et al. and Ayhan et al., any survival difference couldn't be demonstrated between the groups having $\mathrm{RH}$ or $\mathrm{SH}$ and RT. ${ }^{10,11}$ Cohn et al. reported improved survival relative to the historical controls in particular with radical compared with simple hysterectomy in their large series. ${ }^{12}$ Additionally, Boente et al. showed an increased difference in survival with RH in case there is gross cervical involvement. ${ }^{13}$ Nevertheless, others suggested that SH instead of RH may be a sufficient treatment for the patients with clinical cervical involvement, while others recommended the same for only the patients with microscopic cervical involvement. ${ }^{14,15}$ In our study, 38 patients received SH and 15 patients had $\mathrm{RH}$.

There is also no consensus on the necessity and type of adjuvant therapy. SEER data mentioned above showed no significant survival difference with the addition of radiotherapy in the $\mathrm{RH}$ and $\mathrm{SH}$ groups. ${ }^{8}$ Jorge et al. also couldn't demonstrate a survival advantage with the addition of adjuvant radiotherapy to surgery. ${ }^{16}$ Cannon et al. reported low recurrence rates after surgery and adjuvant radiotherapy for stage II endometrial cancer and suggested that brachytherapy without external radiotherapy will be sufficient for low risk patients having completed surgical staging with systematic lymphadenectomy. ${ }^{17}$ Other authors also showed low loco-regional recurrence rate with adjuvant radiotherapy with low toxicities. ${ }^{18,19}$ Systemic therapy is also considered as an adjuvant therapy in order to prevent systemic recurrences. However, the preliminary results of GOG 249 trial approximately $25 \%$ of which was composed of patients with stage II endometrial cancer reported that there was no difference between patients taking adjuvant pelvic radiotherapy and patients taking adjuvant vaginal brachytherapy + chemotherapy. Two patients in the SH group who had adjuvant radiotherapy and 2 patients in the $\mathrm{RH}$ group who didn't take adjuvant treatment had recurrence in our series. There was no statistically significant difference between the $\mathrm{RH}$ and $\mathrm{SH}$ groups in terms of recurrence $(p=0.53)$.

Endometrial cancer involving the cervix presents with a higher rate of lymph node metastasis. ${ }^{20}$ However, the necessity and the extent of lymphadenectomy are still controversial in endometrial cancer. An analysis of SEER data by Chan et al. reported no survival advantage of lymphadenectomy in patients with stage I endometrial cancer. Nevertheless, subgroup analysis of patients with grade 3 stage I disease and patients with stage II and more advanced disease showed improved survival. ${ }^{21} \mathrm{~A}$ complete lymphadenectomy would have a prognostic and therapeutical value and would help to the detection of the patients with stage IIIc disease, and sterilize pelvis and so preclude the need for adjuvant radiotherapy in patients with stage II disease. However, there are few studies including patients having complete pelvic and paraaortic lymphadenectomy with stage II endometrial cancer. Additionally, in most of these, numbers of lymph nodes harvested were low and only a proportion of the patients, not all, received lymphadenectomy. By radical hysterectomy and complete pelvic and paraaortic lymphadenectomy without adjuvant therapy Ayhan et al. reported excellent survival in stage II endometrial cancer cases. ${ }^{11}$ In our study, systematic pelvic and paraaortic lymphadenectomy was performed for all the patients with stage II disease and the number of harvested lymph nodes below 60 was associated with higher risk of recurrence. This was also supported by a study by Lutman et al. suggesting that women with stage I and II endometrial cancer and high-risk histology or high-intermediate risk status had significantly improved survival when a larger number of pelvic lymph nodes were histologically evaluated. ${ }^{22}$

In the present study, totally 4 patients $(9.5 \%)$ had recurrence. The recurrence was in the pelvis in two 
patients (patients 2 and 3). One patient (patient 4) had recurrence both in the pelvis and lung. The last patient (patient 1) had recurrence in the lung. In other studies, recurrence rates ranging between 13\% and $17 \%$ were reported, while more than half of the patients had distant failure, demonstrating a tendency to distant recurrences similar to our study. ${ }^{11,16,23}$ What is different in our study was the salvage of the patient with lung metastasis, while mortality after distant failure was reported to be high. ${ }^{11,19}$ She has been free of disease for 5 years.

Grade, depth of myometrial invasion, LVSI and age and their different combinations were reported to be prognostic factors for stage II endometrial cancer in different studies. ${ }^{11,16-18}$ In our study, age $\geq 57$, depth of myometrial invasion being $1 / 2$ or greater and the number of harvested lymph nodes below 60 were found to be associated with recurrence.

In conclusion, stage II endometrial carcinoma is a rare entity. Preoperative diagnosis is difficult. What is more, surgical and adjuvant treatments are at the discretion of the dealing physicians. Most of the studies in the literature are retrospective and the groups compared are heterogeneous. Since then, management should be individualized and the risk factors for recurrence, the type of hysterectomy and extent of lymphadenectomy performed should be taken into consideration in the planning of adjuvant treatment. If we assume that we could sterilize parametria and the lymph node regions by $\mathrm{RH}$ and systematic lymphadenectomy that has a therapeutic value and could provide a decrease in recurrence, then we may preclude the need for external radiotherapy. Systemic adjuvant therapy may be involved in the first-line treatment plan in order to prevent distant failures, since they continue to be responsible for the most of the recurrences and mortality despite radical surgeries and different protocols of adjuvant radiotherapy.

\section{REFERENCES}

1. Eser SY and Karakılınç H. Cancer Incidence in Turkey. Chapter 1.6 page: 35-51, In: Cancer Control in Turkey. Tuncer AM, Özgül N, Olcayto E and Gültekin M (eds). Ministry Publication Number: 776, Ankara, 2010.

2. Creasman WT, Odicino F, Maisonneuve $P$, et al. Carcinoma of the corpus uteri. FIGO 26th Annual Report on the Results of Treatment in Gynecological Cancer. Int J Gynaecol Obstet
95 Suppl 1:S105-43, 2006.

3. Benedet JL, Bender $\mathrm{H}$, Jones $3 \mathrm{rd} \mathrm{H}$, et al. FIGO staging classifications and clinical practice guidelines in the management of gynecologic cancers. FIGO Committee on Gynecologic Oncology. Int J Gynaecol Obstet 70: 209-262, 2000.

4. Creasman W. Revised FIGO staging for carcinoma of the endometrium. Int J Gynaecol Obstet 105: 109, 2009.

5. Prat J. Prognostic parameters of endometrial carcinoma. Hum Pathol 35: 649-662, 2004.

6. Heyman J, Reuterwall O, Benner S. The Radiumhemmet experience with radiotherapy in cancer of the corpus of the uterus. Acta Radiol 22: 13-98, 1941.

7. Kottmeier HL. The classification and clinical staging of carcinoma of the uterus and vagina. J Int Fed Gynaecol 1: 83-93, 1963.

8. Cornelison TL, Trimble EL, Kosary CL. SEER data, corpus uteri cancer: treatment trends versus survival for FIGO stage II, 1988-1994. Gynecol Oncol 74: 350-355, 1999.

9. Mariani A, Webb MJ, Keeney GL, et al. Role of wide/radical hysterectomy and pelvic lymph node dissection in endometrial cancer with cervical involvement. Gynecol Oncol 83: $72-$ 80, 2001.

10. Eltabbakh GH, Moore AD. Survival of women with surgical stage II endometrial cancer. Gynecol Oncol 74: 80-85, 1999.

11. Ayhan A, Taskiran C, Celik C, Yuce K. The long-term survival of women with surgical stage II endometrioid type endometrial cancer. Gynecol Oncol 93: 9-13, 2004.

12. Cohn DE, Woeste EM, Cacchio S, et al. Clinical and pathologic correlates in surgical stage II endometrial carcinoma. Obstet Gynecol 109: 1062-7, 2007.

13. Boente MP, Edgardo LY, Mclntosh DG, et al. Prognostic factors and long-term survival in endometrial adenocarcinoma with cervical involvement. Gynecol Oncol 51: 316-322, 1993.

14. Leminen A, Forss M, Lehtovirta P. Endometrial adenocarcinoma with clinical evidence of cervical involvement: accuracy of diagnostic procedures, clinical course, and prognostic factors. Acta Obstet Gynecol Scand 74: 61-66, 1995.

15. Tamura H, Nakai $Y$, Nagano $T$, et al. Treatment and prognosis of PT2 endometrial carcinoma. Nihon Sanka Fujinka Gakkai Zasshi 43: 315-320, 1991.

16. Orezzoli JP, Sioletic S, Olawaiye A, et al. Stage II endometrioid adenocarcinoma of the endometrium: clinical implications of cervical stromal invasion. Gynecol Oncol 113: 316-323, 2009.

17. Cannon GM, Geye H, Terakedis BE, et al. Outcomes following surgery and adjuvant radiation in stage II endometrial adenocarcinoma. Gynecol Oncol 113: 176-180, 2009.

18. Pitson G, Colgan T, Levin W, et al. Stage II endometrial carcinoma: prognostic factors and risk classification in 170 patients. Int J Radiat Oncol Biol Phys 53: 862-867, 2002.

19. Blake P, Lodge N, A'Hern RP. An audit of outcome of adjuvant post-operative radiotherapy for 52 women with stage II carcinoma of the endometrium. Br J Radiol 73: 987-993, 2000. 
International Journal of Hematology and Oncology

20. Creasman WT, Morrow CP, Bundy BN, et al. Surgical pathologic spread patterns of endometrial cancer. A Gynecologic Oncology Group Study. Cancer 60 (8 Suppl): 2035-2041, 1987.

21. Chan JK, Wu H, Cheung MK, et al. The outcomes of 27,063 women with unstaged endometrioid uterine cancer. Gynecol Oncol 106: 282-288, 2007.

22. Lutman CV, Havrilesky LJ, Cragun JM, et al. Pelvic lymph node count is an important prognostic variable for FIGO stage I and || endometrial carcinoma with high-risk histology. Gynecol Oncol. 102: 92-97, 2006.

23. Cozad SC. Stage II adenocarcinoma of the endometrium: adjuvant radiotherapy and recurrence patterns. Int $\mathrm{J}$ Radiat Oncol Biol Phys 71: 205-212, 2008.

\section{Correspondence}

Dr. Işın ÜREYEN

Etlik Zübeyde Hanım Kadın Hastalıkları

Eğitim ve Araştırma Hastanesi

Onkoloji Bölümü

Etlik Caddesi

06010, Kecioren, ANKARA / TURKEY

Tel: (+90.312) 3220180

Fax: (+90.312) 3238191

e-mail: isin.ureyen@gmail.com 